\title{
One side strengthening of masonry walls with self-compacting concrete
}

\author{
N. Torunbalci ${ }^{1}$, I. Ediz $^{2} \&$ F. Sutcu ${ }^{1}$ \\ ${ }^{I}$ Faculty of Architecture, Istanbul Technical University, Turkey \\ ${ }^{2}$ Institute of Science and Technology, Istanbul Technical University, \\ Turkey
}

\begin{abstract}
One of the most popular methods of strengthening masonry structures is the application of shotcrete or standard concrete on steel wire mesh reinforcement coated on structural walls. The drawback in shotcrete application is that the width of the formwork for the standard concrete should be made narrow and this causes difficulty in placing and compacting. Where self-compacting concrete is used, however, such problems are eliminated completely. This study experimentally investigates the behaviours of brick masonry wall samples strengthened by self-compacting concrete and standard concrete on one side and includes a key study to represent an example of application on historical structures.

Keywords: masonry, self-compacting concrete, brick masonry, one side retrofitting.
\end{abstract}

\section{Introduction}

Compared to reinforced concrete and steel structures, masonry structures exhibit inferior performance against the lateral loads induced by, for example, earthquakes, etc. In this context, it is crucial to have the existing masonry structures protected against the earthquakes by increasing their strength.

Damage on the masonry structures is attributable to inferior soil parameters, non-conformity with requirement of relevant codes, defective design and application and wear and tear. As a result, earthquakes cause major damage to the structure or else, result in the collapse of the structure as a whole. It is therefore necessary to strengthen buildings with a weak structural system and 
structures already damaged in past earthquakes before major earthquakes. The most popular method used is the strengthening of the present wall by using shotcrete or standard concrete with steel wire mesh reinforcement.

However, many problems are usually experienced in practice. Placing and compacting of the concrete cannot be carried out effectively, due to the narrow formwork. Increasing the thickness of the concrete layer can eliminate the problem; however this in turn gives rise to undesirable loss of the footing area. Such a type of strengthening is therefore not preferred, even if it greatly contributes to the structural performance. If self-compacting concrete is used, the foregoing problems can be solved effectively. Based on the foregoing arguments, the experimental investigations have been conducted in this study [1] on the masonry structures. Unreinforced masonry walls, URM, are used to simulate the masonry structural walls, and they are strengthened with the self-compacting concrete and standard concrete with steel wire mesh reinforcement. A comparison of improvements was achieved in the load-bearing and deformation capacities. It was found out that the strength and the energy dissipation capacities of the masonry walls are significantly improved when strengthened with self compacting concrete.

Many studies have been carried out concerning the methods used for the strengthening of masonry walls. On the other hand, it can be seen, upon an investigation on the literature, that a very limited number of studies are available concerning the application of standard concrete with the steel wire mesh reinforcement. One can come across with no studies on strengthening by contemporary concrete technology, i.e., self-compacting concrete.

\section{Literature survey}

Shing et al. [2] investigated the influence of the horizontal and vertical strengthening ratio of the strengthened walls' ductility, energy dissipation capacities, stresses and lateral resistances. Conducted on concrete masonry and brick samples, the study incorporates hollow blocks filled with mortar and strengthened with horizontal and vertical reinforcement. It has been found out that, vertical strengthening increases the bending strength of the wall and that the diagonal cracks formed as a result of the shear forces depend on the number of the steel s trips used horizontally and vertically and that increasing the ratio of the reinforcement increases the ductility energy dissipation capacity.

Experiments were carried out on samples with and without reinforcement in another study by Drysdale and Khattab [3] to investigate the in-plane behaviours of the concrete masonry walls that are plastered, strengthened and subjected to biaxial loading. Sample walls were constructed with strengthening elements placed at various angles depending on the loading setup and joints that are parallel and orthogonal to the strengthening joints. Experimental works on the brick wall samples without reinforcement reveals that failures are observed in the form of the vertical cracks when loading at $0^{\circ}$ and $90^{\circ}$ with respect to the joints, whereas bad joint failures are observed during inclined loading at $45^{\circ}$ to the joints. In loading reinforced samples, however, vertical cracks formed at $0^{\circ}$ and 
$45^{\circ}$, whereas at $67.5^{\circ}$, the failures are due to the shears of the joints. It is observed that strengthening insures considerable improvement in the deformations. As a conclusion, it is established that the strength and deformation characteristics of the plastered concrete masonry walls depend on the gradients of the joints and the brittle behaviour is prevented so long as the strengthening against the shear, which also contributes to the strength and ductility, is provided. Behaviours of typical residences constructed in rural areas [4] were investigated in a research carried out on half scale brick masonry buildings under cyclic loading and looking at the improvement obtained by strengthening via reinforced concrete bonds. The strengthening is provided on the vertical $\mathrm{r} / \mathrm{c}$ bonds in combination with lintel band and sill-band that are associated with them. In repair works, steel wire mesh reinforcements, which are plastered by cement and epoxy based mortar, are installed. Following the experiments conducted with the samples $1.8 \mathrm{~m} \times 1.8 \mathrm{~m} \times 1.5 \mathrm{~m}$ in size, it was found out that lintel bands and sill-bands are effective in minimizing the cracks at the bottom. On cracked portions, the steel wire mesh reinforcements accompany epoxy based mortar. This contributes to the ductility and deformation capacities. Where the steel wire mesh reinforcement and cement base mortar are used, however, the models undergo the brittle failure; however they exhibit a high level of strength.

\section{Test plan}

All 12 brick wall samples about $185 \times 185 \mathrm{~mm}$ in size are used in the experiments. Brick wall samples are erected for the experiment by using the bricks in standard sizes of $190 \mathrm{~mm} \times 90 \mathrm{~mm} \times 50 \mathrm{~mm}$, reduced to the size $95 \mathrm{~mm} \times 45 \mathrm{~mm} \times 25 \mathrm{~mm}$. At the initial stage, 6 of these brick wall samples were subjected to loading until severe damage occurred.

Thus, 4 different series consisting of three brick wall samples are formed prior to the strengthening according to their states, i.e., non-damaged or predamaged and to the type of strengthening provided.

A notation is adopted for the brick wall samples in accordance with the type of strengthening. Thus, D stands for the pre-damaged brick wall samples, ND for non-damaged samples, SC for self-compacting concrete and $\mathrm{C}$ for standard concrete. Accordingly, ND-SC stands for the non-damaged samples strengthened by self-compacting concrete. Likewise, D-C stands for the pre-damaged samples strengthened by standard concrete.

\subsection{Properties of materials incorporated}

The joints of the brick wall samples are accepted as $5 \mathrm{~mm}$ and therefore, the average grain size of the sand is selected as $1 \mathrm{~mm}$. The specific weight of the sand is $2650 \mathrm{~kg} / \mathrm{m}^{3}$. Type PC 32.5 and Type PC 52.5 grade cement are used in the mortars for erecting the brick wall samples and the top rows of the brickwork, respectively. The specific weight of the cement is $3125 \mathrm{~kg} / \mathrm{m}^{3}$.

The mortar used in erecting brick wall samples has the cement/sand ratio of $1: 3.5$ and the wet mortar consistency as prescribed by the flow table testing is 1.48. The specific weight of the mortar is $2130 \mathrm{~kg} / \mathrm{m}^{3} .9$ samples $40 \times 40 \times 160 \mathrm{~mm}$ 
in size were prepared in order to determine the mortar strength and these samples were tested in experiments in groups of three on the $7^{\text {th }}, 14^{\text {th }}$, and $28^{\text {th }}$ days, respectively. The average mortar compressive strengths on the $7^{\text {th }}, 14^{\text {th }}$, and $28^{\text {th }}$ days are $8.33,11.78$ and $16.24 \mathrm{~N} / \mathrm{mm}^{2}$, respectively.

In repairing the pre-damaged brick wall samples, epoxy resin is employed. This is a two-part, solvent free epoxy resin that can be used in humid environments.

The steel wire mesh with a plain surface and a wire diameter of $\varnothing 3$, manufactured from S500 grade steel and braided with a grid spacing of 50x50 $\mathrm{mm}$, is provided to supplement the strengthening process to strengthen reinforcement. To simulate the actual application, the experiment is performed by using steel wire mesh, but since ribbed wire is not available in suitable diameter and grid spacing, plain steel wire mesh is added for the reinforcement

Self-compacting concrete has a spread diameter of $0.75 \mathrm{~m}$ and specific weight of $2.350 \mathrm{~kg} / \mathrm{m}^{3}$. Compressing strength of the self-compacting concrete is tested on samples settled on the steel formworks sized 40x40x160mm. The samples are tested by the compressive testing apparatus capable of exerting $200 \mathrm{KN}$ on the $7^{\text {th }}, 14^{\text {th }}$, and $28^{\text {th }}$ days following concrete settling. The respective compressive strengths are determined as $40.33,45.38$ and $56.39 \mathrm{~N} / \mathrm{mm}^{2}$.

While determining the compressive strength of the standard ready-mixed concrete with a maximum grain diameter of $12 \mathrm{~mm}$, cubic samples $150 \times 150 \times 150 \mathrm{~mm}$ in size are tested. The compressive strengths on the $7^{\text {th }}, 14^{\text {th }}$, and $28^{\text {th }}$ days are determined as $24.00,29.18$ and $38.80 \mathrm{~N} / \mathrm{mm}^{2}$, respectively.

\subsection{Test schedule}

After the brick wall samples have been cured for one week, they are kept under the ambient temperature until the $28^{\text {th }}$ day. Heads are constructed on the opposite corners of brick masonry walls with a cement grade of 52.5 and a cement/sand ratio of 1:3.5.

The brick wall samples were mounted on the testing rig in such a way so that the bed joints formed an angle of $45^{\circ}$ with the direction of vertical loading. The crack propagation is observed and recorded by measuring the load-deformations via the mechanic strain gauges (Fig.1).

Six brick wall samples were strengthened with self-compacting concrete and 6 with standard ready-mixed concrete. 3 from each group were first subjected to loading until severe damage occurred. All cracks induced on the pre-damaged walls are repaired with epoxy resin. Then, steel wire mesh reinforcements are fixed at about $10 \mathrm{~mm}$ in front of the surfaces of the brick wall samples so that they are located at the centre of the concrete layer of $20 \mathrm{~mm}$ thick on surfaces of the samples as shown in Figure 2.

Self-compacting concrete supplied from the concrete plant is applied on the surface of 3 pre-damaged and 3 non-damaged URM wall samples in layers 20 $\mathrm{mm}$ thick. The samples with strengthening provided by self-compacting concrete on one side only are kept in the formwork for 48 hours to get hardened. At the 
end of that period, brick wall samples are provided with the same strengthening on other sides and are subjected to curing.

In order to compare the self-compacting concrete with the standard concrete, a total of 6 brick wall samples consisting of 3 pre-damaged and 3 non-damaged samples, are strengthened by standard concrete on one side.

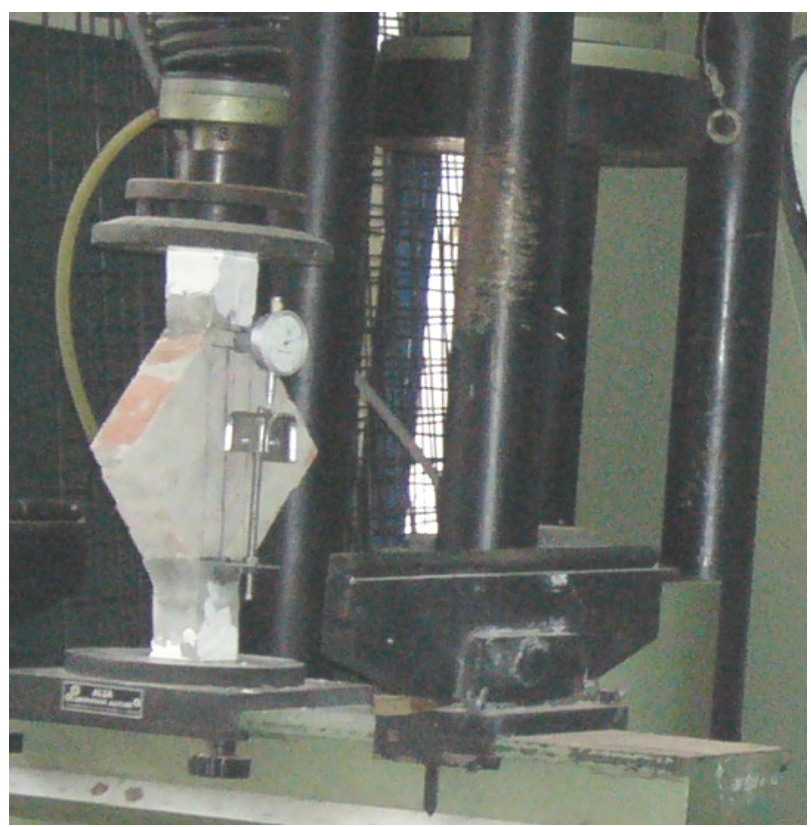

Figure 1: $\quad$ Experimental layout and brick wall specimens.

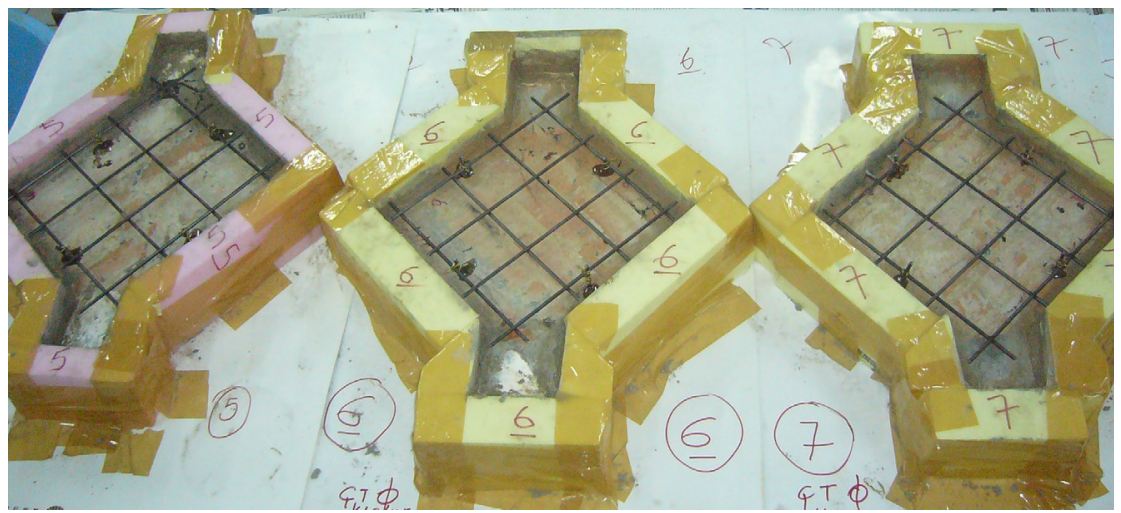

Figure 2: $\quad$ Fixed steel wire mesh reinforcements. 


\section{Evaluation of the results of the experiments}

This section provides the evaluation of the results of the experiments carried out on the brick wall samples, and the discussion on the effect of retrofitting of the masonry structures after having been strengthened by self compacting concrete and standard concrete accompanied by steel wire mesh reinforcement applied on the load bearing capacities of such structures.

Experiments are performed on 12 brick wall samples from 4 different series. The failure loads of brick wall samples including URM walls are provided under Table 1, whereas Figure 3 illustrates the load deformation relations for overall test results. In Table $1 \mathrm{COV}$ represents the coefficient of variation as 3 specimens were used for each group.

Table 1: $\quad$ Maximum compressive strengths of specimens.

\begin{tabular}{|c|c|c|c|c|}
\hline & & \multirow{2}{*}{ Specimen } & \multicolumn{2}{|c|}{ Max. compressive strength } \\
\hline & & & Average (MPa) & $\operatorname{COV}(\%)$ \\
\hline \multirow{2}{*}{ 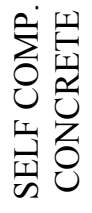 } & Damaged & $\mathrm{D}-\mathrm{SC}$ & 49.33 & 17.48 \\
\hline & $\begin{array}{l}\text { Non } \\
\text { Damaged }\end{array}$ & ND-SC & 57.8 & 12.11 \\
\hline \multirow{2}{*}{ 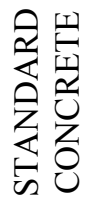 } & Damaged & $\mathrm{D}-\mathrm{C}$ & 44.0 & 18.04 \\
\hline & $\begin{array}{l}\text { Non } \\
\text { Damaged }\end{array}$ & ND-C & 34.66 & 21.84 \\
\hline \multicolumn{2}{|c|}{ URM WALL } & URM & 18.6 & 15.9 \\
\hline
\end{tabular}

As provided under the table and figures, the strengths of brick wall samples as strengthened on one side vary depending on numerous parameters. The load bearing capacities of the walls strengthened on one side are to a great extent. On the other hand, the deformations are naturally decreased when additional strengthening is provided. The degree of decrease in the deformation stands at 10 per cent.

The highest ultimate failure loading and stress capacities are observed on NDSC brick wall samples, i.e., non-damaged samples strengthened by self compacting concrete with steel wire mesh reinforcement. The lowest failure loading is observed in ND-C brick wall samples, i.e., undamaged samples strengthened by standard concrete with steel wire mesh reinforcement. On the 
other hand, performance of the reinforced walls is quite acceptable. It is likely that desirable results can be obtained when strengthening is provided on one side of the walls of the masonry structures using self-compacting concrete with reinforcement. Taking into consideration the fact that the adjoining building will only allow for strengthening on the inner sides, it is clear that this will also provide considerable improvement in the load bearing capacities.

\subsection{Comparison of the results for brick wall samples strengthened by self-compacting concrete and standard concrete}

Experiments have been performed on 12 brick wall samples in 4 different series strengthened by standard concrete and self-compacting concrete. Figure 4 illustrates the average failure load of the brick wall samples series.

Compared to those strengthened with standard concrete, the behaviours of non-damaged brick wall samples strengthened with self compacting concrete change to great extent. The increases in failure loading capacity stand between 100 percent and 170 per cent when strengthened with standard concrete and with self compacting concrete, respectively. Similar improvements are observed in deformations as well.
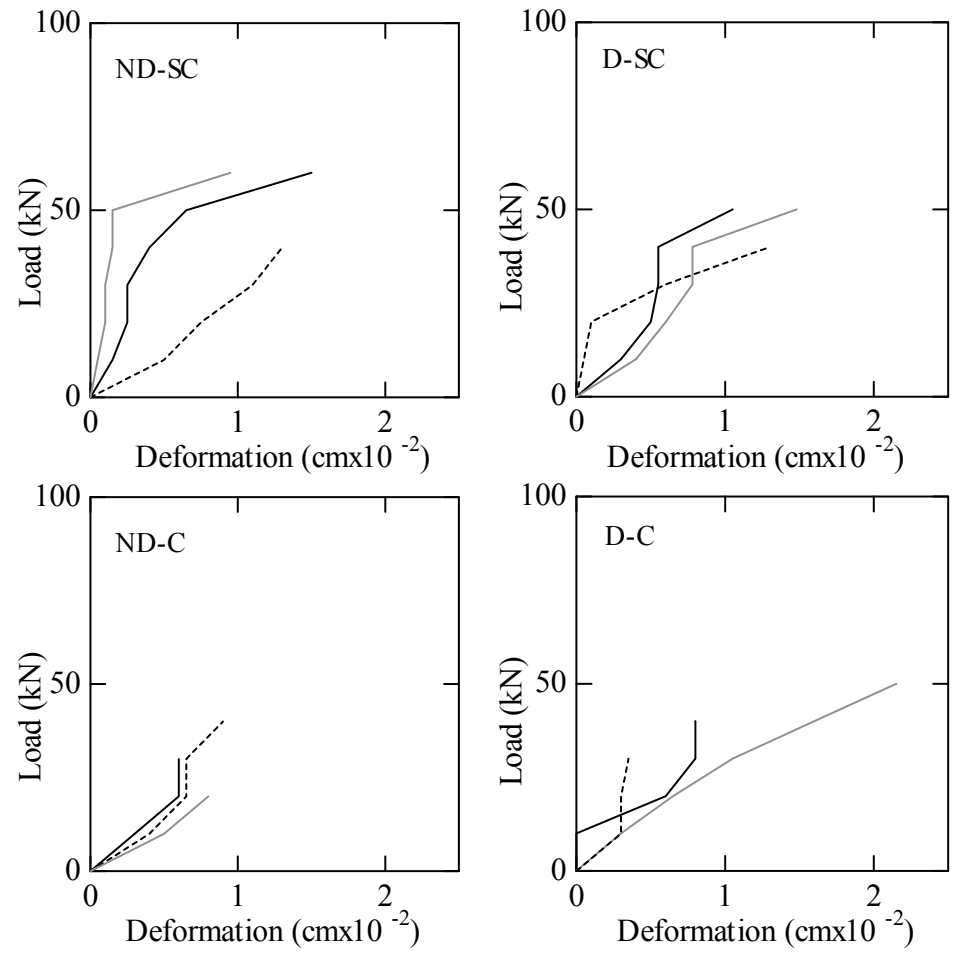

Figure 3: Load-deformation relation of wall specimens strengthened by self-compacting concrete and standard concrete. 


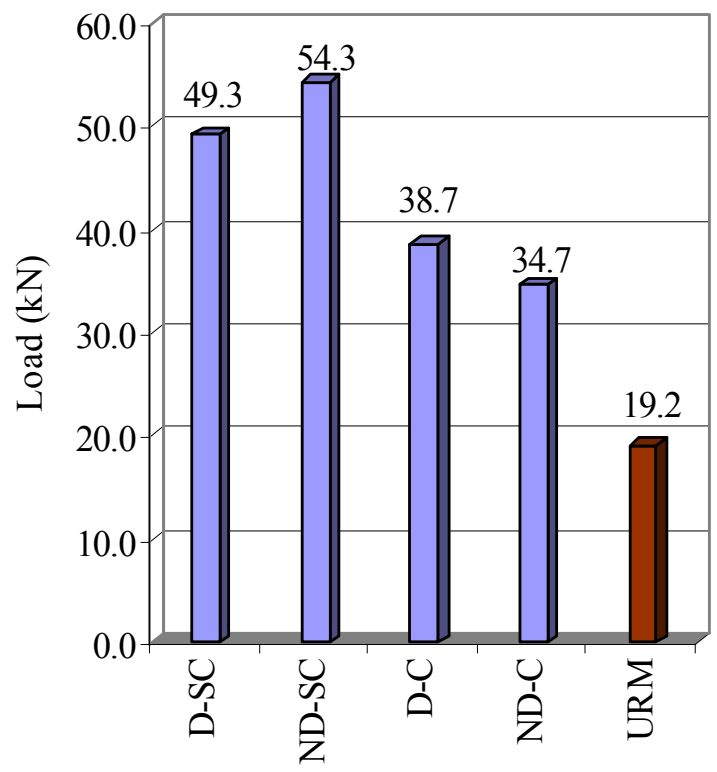

Specimen

Figure 4: Comparison of average failure loads of brick wall samples following self-compacting concrete-standard concrete strengthening.

No significant improvement has been achieved with the pre-damaged brick wall samples close to their failure points and repaired with epoxy resin, no matter if they are strengthened by self-compacting concrete. In some cases, brick wall samples strengthened with the standard concrete, however, exhibit slight improvement. The behaviour of the brick wall samples is closely related to the status, character, and number of the cracks formed during pre-loading of the samples and the quantity of the epoxy resin used in repairing the cracks formed. The brick wall samples incur damages at their weakest portion during the preloading process carried out to induce damage. These cracks are generally repaired along the compression diagonal and that provides significant increase in the strengths of these portions compared to the other portions. It is therefore highly likely that this, rather than the type of the concrete used in strengthening is the main factor defining both the failure and deformation behaviours of the samples.

Another point that deserves emphasis here is that the sizes of the brick wall samples are small and therefore, the repaired portion of the wall covers the majority of evident when observing the behaviours of non-damaged brick wall samples. Self-compacting concrete has advantages over standard concrete with regard to better encasing of the reinforcement, providing a better bond between the reinforcement layer and the wall surface, self-compacting and self-levelling and featuring the nonporous wall surface area. It is evident that the role of the repair with epoxy resin will decrease as the walls become bigger or actual. 
The improvement obtained by strengthening with the self-compacting concrete is obvious in the behaviour of non-damaged wall samples. This stands on the fact that, self-compacting concrete encases the reinforcement better, the bond between self-compacting concrete and the wall is stronger, self levelling advantage and the nonporous structure of the material. Higher deformation caused by self-compacting concrete can be explained by the fact that self compacting concrete exhibits more ductile behaviour compared to standard concrete.

\section{Conclusions and discussion}

The URM walls usually collapse upon formation of the cracks along the loading axis or else, in line with the joints or in line with both the orientations of joints and the bricks (Figure 5).

In some cases specimens break into pieces. It is determined that strengthened brick wall samples were not broken into pieces. Following strengthening, URM wall samples feature significant increase in their load-bearing capacities. On the other hand, the deformations of the brick wall samples decrease to a great extent.

When strengthening is applied to the brick wall samples, the load-bearing capacities tend to become dependent on numerous parameters. It is therefore unlikely to state the exact ratios. For the purpose of approximation, it can be concluded that the load-bearing capacities of the URM wall samples strengthened on one side are increased by 170 per cent when strengthened with self compacting concrete.

Strengthening of pre-damaged brick wall samples by self-compacting concrete provides significant change in their behaviours, as compared to the standard concrete. This positive change is not, however, observed in some predamaged samples. The behaviour of the brick masonry wall samples is closely related to status, character, and number of the cracks formed during pre-loading of the samples and the quantity of the epoxy resin used in repair of the cracks formed. Repair of these cracks are generally performed along the compression diagonal however, this ends up with significant increases in their strengths of these portions compared to the other portion of the samples. It is likely that the failure or deformation behaviours of the samples are determined by that, rather than the type of the concrete used in strengthening.

Another point to be emphasized here is that the sizes of the brick masonry wall samples are small and therefore, the repaired portion of the wall covers the majority of the wall surface area. It is evident that the role of the repair with epoxy resin will be reduced for bigger or true size walls. The improvement obtained following strengthening with the self-compacting concrete is evident when observing the behaviours of non-damaged brick masonry wall samples.

Where the samples are strengthened by the standard concrete, no significant difference is observed between the load-bearing capacities of pre-damaged and non-damaged brick wall samples. In fact, the samples strengthened without predamaging would be expected to perform better, however it is likely that the repair with epoxy resin contributes to the damaged samples' strengths in excess non-damaged ones. 


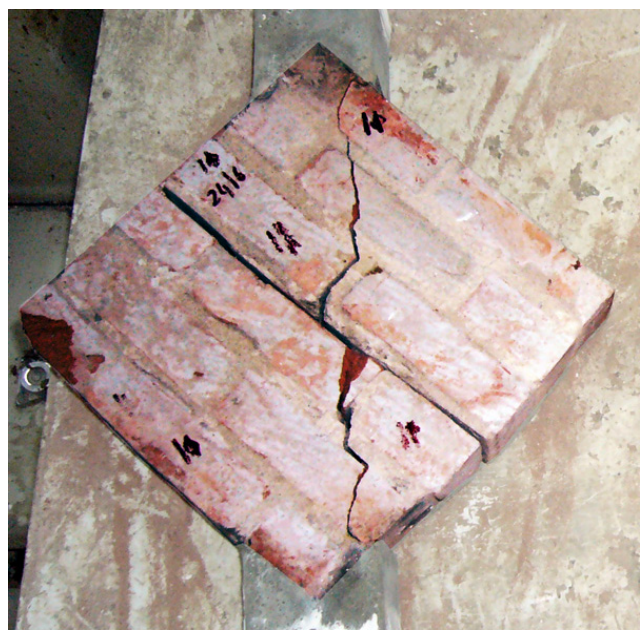

Figure 5: $\quad$ Failure mode of a URM wall specimen.

The fact that the samples' surfaces repaired with epoxy resin reduces the concrete adherence to the surfaces, which gives rise to such peculiar behaviour. The inclusion of the steel wire mesh reinforcement in the concrete aggravates this effect. This is mainly because the loss of adhesion may give rise to premature separation that prevents the occurrence of the expected behaviour.

The impermeability of the self-compacting concrete is twice as much as compared with the standard concrete. In strengthening the masonry structures, the service life will be improved, let alone increasing the load-bearing capacities.

Furthermore, it is possible to obtain superior surface smoothness in strengthening as compared with the standard concrete, thanks to the selfcompacting concrete's self-placing, self-levelling and nonporous strengthening properties. This also eliminates the need for the plaster, thus reducing the time and labour for strengthening. In strengthening process, the quality attributes are maintained during handling and settling of the concrete, which might be preferable. Furthermore, it is determined that the adherence obtained between the layer and the brick wall is better in case of the self-compacting concrete as compared to the standard concrete.

On the other hand, the adherence might adversely be affected when the epoxy resin is used in repairing pre-damaged walls. This might, however, be just the opposite as well. It is therefore necessary to roughen the surfaces repaired with epoxy resin by making use of special process to increase the adherence with the concrete.

\section{Case study}

In Kayseri-city a site conversation area with seven stone houses built around 1900 were restored by the Kayseri Metropolitan Municipality. Some of these are 


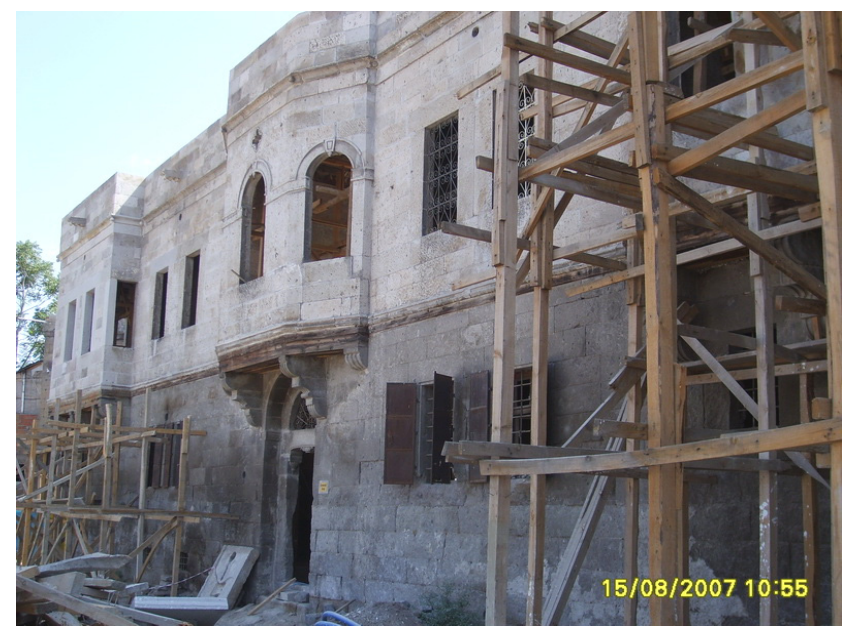

Figure 6: Front wall external view.

mansions and consist of 3 floors including a basement, a ground floor and a first floor. All buildings have a flat roof and built contiguously (Figure 6).

The historical buildings under preservation consist of the tokana/traditional kitchen, the hamam/bath, the köşk/kiosk, the haremlik/woman's section of the house, the selamlı/men's section of the house and the sofa/main hole and represent many historical signs through their banisters, wood carvings and masonry ornaments.

For the repairing of cracks on masonry walls at the basement and upper floors, epoxy resin injection was used partially and for the inner walls CFRP was applied. CFRP application was accepted by the authority in charge for the inner walls and the inner sides of external walls as they were later covered with timber lining.

Kuyumcuoglu Mansion, which is one of the restored stone houses in question, had out-of-plane deformations on the front face of ground floor walls caused by the inner side section loss. The deformation does not seem to affect the appearance of the building; however repair was inescapable as the safety of the structure was threatened.

Section loss in question reduced the thickness of the front walls from the original $25 \mathrm{~cm}$ to $10-12 \mathrm{~cm}$. Application of CFRP was not a suitable solution because of the extreme section loss. What should have done here was to keep the original front face and thicken the section using similar stones in the inner side. However, as the original part of the wall was insufficient for bearing loads, it was decided to use self-compacting concrete of $10 \mathrm{~cm}$ thick on wire mesh reinforcement and cover the inner surface with a thin layer of the original stones which makes the total thickness $25 \mathrm{~cm}$ again. Wire mesh reinforcement was fixed on the inner surface by using steel connectors and epoxy resin. During the application of self-compacting concrete, the front face of the wall was supported to prevent any collapse. 


\section{Acknowledgements}

The study presented under this article is sponsored by Lafarge-Concrete Turkey. The authors acknowledge for the financial support provided and the Self Compacting Concrete (Agilia) supplied.

\section{References}

[1] Ediz, I. (2006) The experimental study on retrofitting of structural brick masonry walls using steel wire mesh reinforcement and self compacting concrete. M.Sc. Thesis, Institute of Science and Technology, Istanbul Technical University.

[2] Shing, P.B., Noland, J.L., Klamerus, E., Spaeh, H. (1989) Inelastic behavior of concrete masonry shear walls. Journal of Structural Engineering;1159:2204-2225.

[3] Drysdale R. G., Khattab M.M. (1995) In-plane behavior of grouted concrete masonry under biaxial tension-compression. ACI Structural Journal;92-6.

[4] Agarwal P., Thakkar S.K. (2004) A comparative study of strengthening and retrofitting measures for unreinforced brick masonry model under cyclic testing. Journal of Earthquake Engineering;8-6:839-863. 